\title{
Branching pattern and inflorescence bud displacement in Flickingeria (Orchidaceae)
}

Rasmussen, Hanne Nina

Published in:

Nordic Journal of Botany

Publication date:

1982

Document version

Publisher's PDF, also known as Version of record

Citation for published version (APA):

Rasmussen, H. N. (1982). Branching pattern and inflorescence bud displacement in Flickingeria (Orchidaceae). Nordic Journal of Botany, 2, 235-248. 


\title{
Branching pattern and inflorescence bud displacement in Flickingeria (Orchidaceae)
}

\author{
Hanne Rasmussen
}

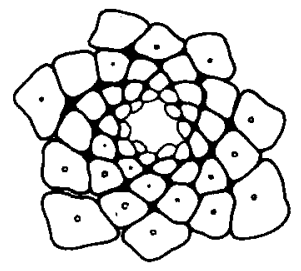

\begin{abstract}
Rasmussen, H. 1982. Branching pattern and inflorescence bud displacement in Flickingeria (Orchidaceae). - Nord. J. Bot. 2: 235-248. Copenhagen. ISSN 0107-055X.

The vegetative architecture of Flickingeria is modular, consisting of three kinds of shoots of determinate growth. Species differ with respect to extent of branching and length of shoots, but branching is normally restricted to a few particular buds, the potential of which depends on their position.

All inflorescences are axillary, although some appear to be terminal. Inflorescences subtended by foliage leaves are displaced into a cavity in the stem, emerging on the abaxial side of the leaf base. The peripheral layers of the stem covering the inflorescence bud may be conspicuously extended and dry up so as to resemble a bract. The arrangement of the inflorescences is a distinctive specific character within the genus. A hypothesis for the evolution of character states is established. The growth and flowering strategy is discussed.
\end{abstract}

H. Rasmussen, Inst. of Plant Anatomy and Cytology, Sølvgade 83, Univ. of Copenhagen, DK-1307 Copenhagen K, Denmark.

\section{Introduction}

The exceptional vegetative features of the orchid genus Flickingeria Hawkes (= Ephemerantha Hunt \& Summerhayes) were first pointed out by the celebrated Dutch orchidologist Blume (1825: 329), and resulted in its exclusion from Dendrobium (as Desmotrichum Bl., see Seidenfaden 1980 for the nomenclatural history). The genus is characterized by the erect, sympodial stems, a condition rarely found in orchids (Rasmussen \& Rasmussen 1979, Dressler 1981). The inflorescences are either seemingly terminal or appear non-axillary below the foliage leaf on its abaxial side, in some cases covered by a bract-like structure. It has long been known that there are specific differences within the genus with respect to the position and number of inflorescences (Dalzell 1852). In the newly published taxonomic revision of the Mainland Asian species (Seidenfaden 1980) vegetative characters as well as inflorescence characters were used extensively for identification of the species. Three conditions with respect to inflorescences were distinguished: (1) the inflores- cences appear only at the top of the stem on the adaxial side of the foliage leaf ("adaxial inflorescence"), (2) the inflorescences appear on the abaxial side of the foliage leaf only ("abaxial inflorescence"), or (3) inflorescences are found in both positions (Seidenfaden 1980: 10, Figs 1-2).

However, no explanation of the peculiar position of the apparently abaxial inflorescence has hitherto been offered, except for Schlechter's (1911-14) suggestion that a twisting of the stem could account for this position.

The emphasis in taxonomic works on tropical orchid genera is frequently entirely on floral characters. However, Holttum (1964) mentioned Dendrobiinae (including Flickingeria) as an example of an orchid group where floral morphology is rather uniform and where studies of the diverse growth-habits may prove particularly rewarding.

The morphological-anatomical study of branching pattern and inflorescence position which is presented here has helped to solve some of the taxonomic prob-

(C) NORDIC JOURNAL OF BOTANY

NORD. J. BOT. 2: 235-248, STRUCT 021, TROP 038

Nord. J. Bot. 2 (3) 1982 


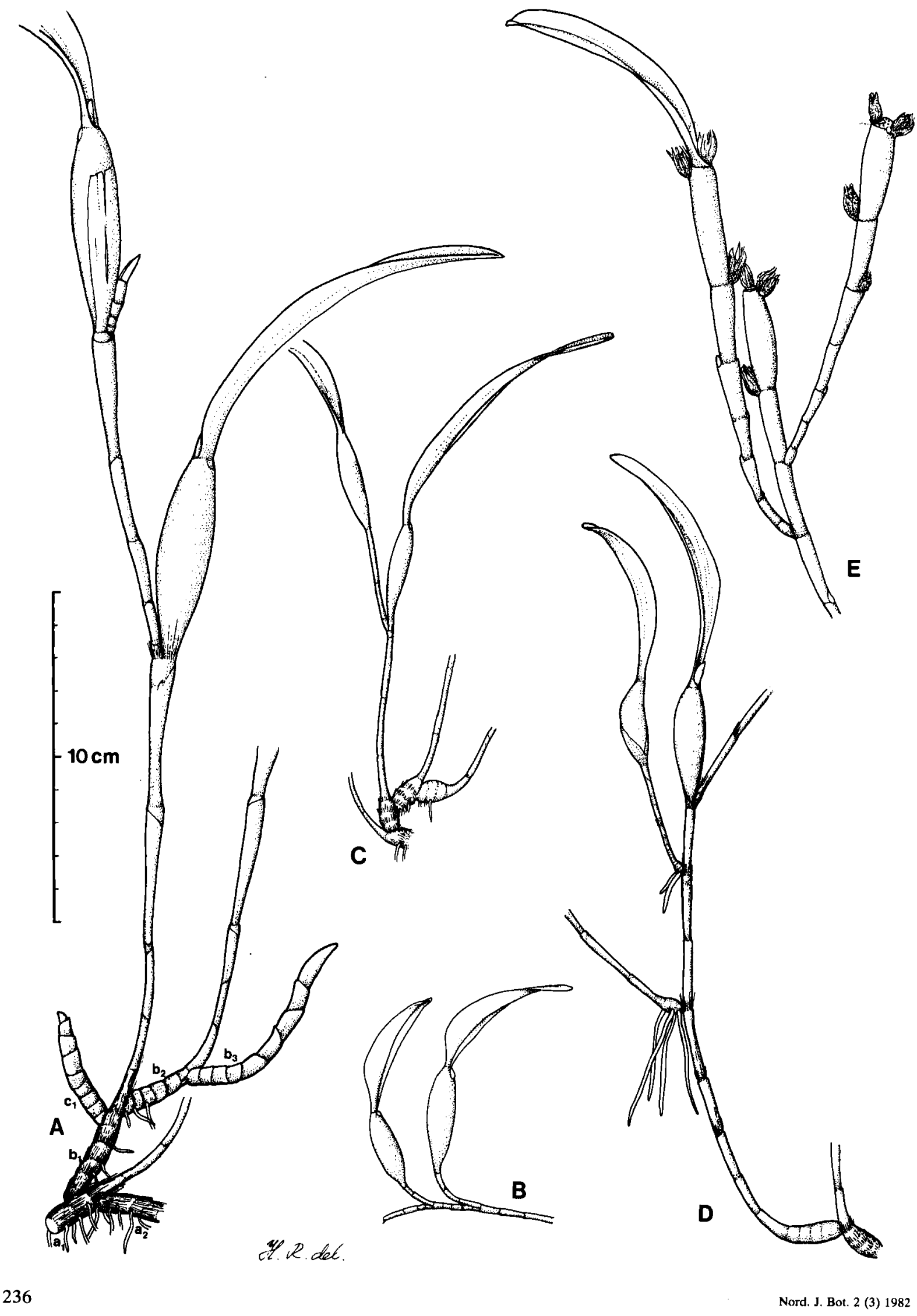


lems in Flickingeria (Seidenfaden 1980). It has clarified how inflorescences have become displaced so as to appear on the abaxial side of the foliage leaf. The most likely course of evolution of the character is demonstrated by specific differences in the extent of displacement. The descriptive term "adaxial" inflorescence introduced as a practical tool in Seidenfaden (1980) is here shown to be somewhat misleading, as this inflorescence, although axillary, has no relation to the foliage leaf. The description in this paper is also corrective to the one used in Seidenfaden (1980) concerning the "bract" covering the "abaxial" inflorescence.

"Abaxial" and other odd positions of axillary buds can be observed in other orchid genera (e.g. Pholidota) and in other monocotyledons: Palmae (Fisher 1973, Fisher \& Dransfield 1979), Musaceae (Fisher 1978), and Liliaceae (Samson \& Karstens 1971).

It appears that the results of this investigation exemplify a widespread monocotyledon phenomenon.

\section{Materials and methods}

The genus Flickingeria Hawkes is estimated to contain about 65-70 species in tropical Asia ranging from India to the Pacific Islands (Seidenfaden 1980). 14 of the 16 species reported from Thailand are studied here. The investigated species represent two of the three sections recognized by Seidenfaden, i.e. sect. Plicatiles and sect. Bilobulatae.

34 living specimens representing 14 species of Flickingeria were available in the Thai orchid greenhouse in the Botanical Garden of Copenhagen (Tab. 1). The living specimens are transplants from the field, and the main part have been in cultivation for several years. It was possible to study the morphological variation within the individuals and follow the growth of the plants for a longer period under the uniform although not specified conditions of the greenhouse. When compared with herbarium specimens of the same species collected in nature, the cultivated plants showed no change of growth-habit due to hothouse conditions.

A number of herbarium specimens representing other Asian species were also examined. The types of growthhabit exhibited in the living Thai material appeared representative of the whole genus. An exception is a kind of growth-habit of some species in sect. Flickingeria, which is not represented in the Thai flora. Species with this habit will be the only non-Thai species treated in some detail here.
Tab. 1. Living specimens investigated, vouchers in spirit collection at $\mathrm{C}$.

Flickingeria sect. Plicatiles Seidenf.

F. fimbriata (Bl.) Hawkes: Ths 388, Ths 389, Cu 1217, GT 6466. -F. parishii Seidenf.: GT 4184, GT 8296, GT 8387. $-F$. compressa Seidenf.: GT 7404. - F. insularis Seidenf.: GT 6481. - F. pardalina (Rchb.f.) Seidenf.: GT 5515, GT 6349, GT 7455. - F. pallens (Ridl.) Hawkes: GT 6276, GT 6327, GT 6430, GT 6461, GT 6465 - F. fugax (Rchb.f.) Seidenf.: GT 7385, GT 7818, GT 7862.- $F$. albopurpurea Seidenf.: $\mathrm{Cu}$ 1359, GT 7170.

Flickingeria sect. Bilobulatae Seidenf.

F. convexa (Bl.) Hawkes: GT 6507a. $-F$. unibulbis Seidenf.: GT 7509. - F. xantholeuca (Rchb.f.) Hawkes: GT 7586. $-F$. angustifolia (Bl.) Hawkes: GT 6290. - F. ritaeana (K. \& P.) Hawkes: GT 3728, GT 7361. - F. bancana (J. J. Sm.) Hawkes: GT 7508, GT 7511, GT 7528, GT 7530, GT 7543, GT 755 la.

Whole young pseudobulbs were cleaved Iongitudinally and cleared in lactic acid (Simpson 1929). The upper part of young pseudobulbs with inflorescence buds was fixed in FAA and embedded in paraffin to obtain transverse serial sections which were stained in Toluidine Blue 0.

Photographs of the fresh and cleared material were taken with a Wild M 400 Macroscope.

\section{Observations}

\section{General architecture}

The species of Flickingeria are perennial, rhizomatous, epiphytic herbs. The main shoots consist of a basal, rhizomatous part rather abruptly turning into a leafy, erect part. A new main shoot sprouts from the bud subtended by the apical scale leaf of the rhizomatous part so that a sympodial rhizome is formed. Branching of the rhizome normally occurs only from the node right below that of the renewal bud (Fig. 1A). The rhizome is plagiotropic, creeping upon the substrate, rooting on the side facing the substrate. The sheathing, membranous, soon fibrous, scale leaves are distichously arranged with a horizontal plane of distichy.

The erect, but still plagiotropic part of the main shoot is usually more slender and with longer internodes than the rhizome and is not rooting. It carries distichous, membranous sheathing scale leaves and is terminated by a swollen internode, i.e. a pseudobulb, above which a single foliage leaf is inserted. The pseudobulb is oval in

Fig. 1. Habits of F. Flickingeria. - A: F. albopurpurea, sympodial renewal of the rhizome (e.g. $b_{1}$ is renewed by $b_{2}$ and further on by $b_{3}$ ) and branching of same (e.g. $c_{1}$ is a branch of $b_{1}$ ). $b_{1}$ itself originated by branching of $a_{1}$. Erect stems (one fully depicted) with ordinary branching. - B: $F$. convexa, creeping rhizome and short, erect unbranched stems. - C: $F$. ritaeana, swollen rhizome with short segments. Erect stem with ordinary branching. - D: $F$. pardalina, ordinary and extraordinary branching. Extraordinary branches somewhat rhizomatous at the base, rooting. - E: $F$. comata, pseudobulbs not distinctly delimited. Flowering at upper nodes of the stem, also in the position of ordinary branching in other species. - A: GT 7170, B: GT 6705, C: GT 3728, D: GT 5515, E: Dissing 2900. A-D drawn from young shoots which have not flowered yet, E from soaked herbarium specimen in flower, leaf reconstructed in drawing. Scale $=10 \mathrm{~cm}$. 
Fig. 2. Schematic representation of architecture in Flickingeria. The three kinds of buds are shaded according to their potentiality, which is indicated to the right. (1) main shoots, (2) branches, (3) inflorescences.

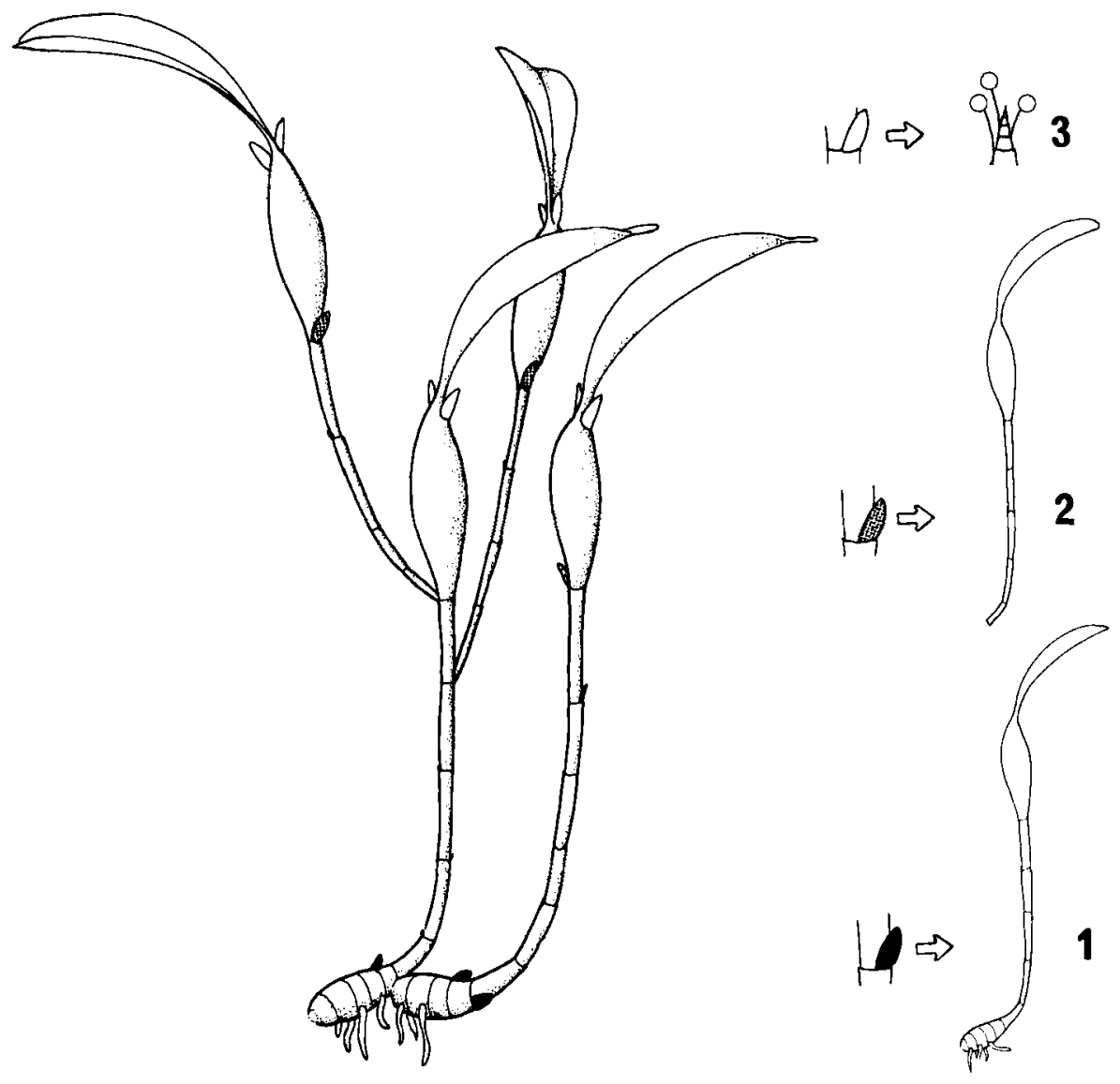

transection, being more extended in the direction of the plane of distichy.

While the membranous leaves of the rhizome and erect stem are sheathing and without lamina, the foliage leaf is non-sheathing, consisting entirely of a conduplicate, linear to ovate lamina. The foliage leaves may be shed at a joint at their base but at least under greenhouse conditions they persist for many years.

Branching of the stems occurs ordinarily at the node right below the pseudobulb (Fig. 1A, C, D). Branches from lower nodes ("extra-ordinary" branches) occur only when ordinary branching on the stem in question has taken place, and only in certain species (Fig. 1D). Branches are like the main shoots in every respect except that they usually have no basal rhizomatous part. The branching process may be repeated many times, 4-5 times is not unusual, so that long erect sympodia are formed.

In some species the pseudobulb is seemingly terminated by a bud which develops into an inflorescence. The inflorescence is actually pseudoterminal, placed in the axil of a leathery bract inserted on the stem right above the foliage leaf in distichous succession. Figure 3A-B shows a transverse section through the base of the axillary inflorescence bud. A third leaf in the suc- cession, also a bract but less leathery than the first one, may be found above and in line with the foliage leaf, and may also subtend an inflorescence. Figure $3 E-F$ shows the two bracts with their axillary buds, $b_{1}$ and $b_{2}$.

In some species, inflorescences are subtended by the foliage leaf. These inflorescences emerge on the abaxial side of the leaf from a cavity in the pseudobulb (Figs $4-6$, to be described further below). The arrangement of inflorescences is a specific character which is treated in more detail under the sections.

The inflorescences are few-flowered racemes, producing many membranous bracts, most of which are sterile. The inflorescences are long-lived and may produce flowers in several seasons, but usually only one at a time. The flowers, on the other hand, are fugacious, lasting only a few hours. Sterile shoots with bracts may develop in place of flowers (Fig. 3E-F, $b_{1}^{\prime}$ and $b_{1}^{\prime \prime}$ ). There is, however, no indication that the bracts of these side shoots ever subtend flowers, thus forming a compound inflorescence.

Hence, the modular architecture exhibited in this genus consists of three kinds of shoots (Fig. 2):

(1) Shoots with a basal rhizomatous part, turning into an erect stem (main shoots). 
(2) Shoots without a basal rhizomatous part only constituting an aerial stem (branches).

(3) Inflorescences.

Shoots of type (1) arise from buds of the rhizome, and are subtended by scale leaves. Shoots of type (2) arise from buds on erect stems below the pseudobulb, and are subtended by scale leaves. Inflorescences ( 3 ) arise from buds on erect stems near the apical end of the pseudobulb, and are subtended by foliage leaves and/or bracts.

Deviation from this pattern is seen only in a few species, where branches tend to be rooting, occasionally somewhat rhizomatous of appearance in their basal part (e.g., F. pardalina, Fig. 1D), hence representing a condition between type (1) and type (2). These exceptional branches are mainly found as extraordinary, lower branches of the species in question. A single species has inflorescences also at the node below that of the foliage leaf (Fig. 1E).

In both horizontal and vertical parts of the axes, the most apical of the axillary buds seems to dominate. In the rhizomatous part, the bud closest to the erect part invariably is the renewal bud, and the bud immediately below this represents the only possibility of branching of the rhizome. No other buds on the rhizome have been seen sprouting except after damage of the rhizome.

Likewise, in the part of the erect stem below the pseudobulb only the bud immediately below the pseudobulb sprouts, and buds at lower internodes may only be developed if the dominant bud has already developed into a branch. In some species such extraordinary branching never occurs. Flowering in the part of the stem above the pseudobulb is not a necessary condition for vegetative branching below.

Above the pseudobulb, any of the possible inflorescences (as enumerated above) may be the one to develop or dominate - also the lowest one subtended by the foliage leaf - dependent on the species.

\section{Section Flickingeria}

Of this section which is estimated to comprise 5-7 species (Seidenfaden 1980) I have seen herbarium material of three, of which only the external morphology was investigated.

In $F$. angulata, the rhizome has about 7 long, thick internodes in each segment. Erect stems branch ordinarily and frequently extraordinarily. Smith (1905) described the pseudobulbous part of the stem as consisting of several internodes of gradually increasing succulence when approaching the foliage leaf. This could not be distinctly seen on the herbarium specimens studied, where the pseudobulbs appeared to consist of one internode only. Inflorescences are leaf-subtended as well as bract-subtended (see Seidenfaden 1980: Fig. 3).

$F$. comata has an architecture like that of $F$. angulata, but inflorescences emerge also at nodes on the erect stems below that of the foliage leaf. The extent of the pseudobulbous part of the stem is not distinctly delimited (Fig. 1E). The architecture of $F$. scopa is similar to that of $F$. comata, but they are possibly conspecific (Seidenfaden, pers. comm.).

\section{Section Plicatiles}

Of this section with presumably about 30 species, 8 Thai species have been investigated: $F$. fimbriata, $F$. parishii, $F$. compressa, $F$. insularis, $F$. pardalina, $F$. pallens, $F$. fugax, and $F$. albopurpurea. Serial sections of the top of the pseudobulbs were studied in all species except $F$. compressa and $F$. pallens.

Various habits are represented in this section. F. fimbriata and $F$. parishii are large plants with long rhizome segments of several internodes (cf. Seidenfaden 1980: Figs 4,7$)$. Their inflorescences are subtended by bracts only. Figure 3 shows the inflorescence bud in the axil of the first leathery bract above the foliage leaf in $F$. parishii, and two inflorescence buds in the axils of two bracts above each other in $F$. fimbriata. In addition. $F$. parishii has a dormant inflorescence bud below the foliage leaf (not seen in Fig. 3) like F. pardalina, see below.

$F$. compressa, F. fugax and F. albopurpurea (Fig. 1A) are smaller plants with rhizome segments shorter than in the two species mentioned above. Inflorescences are positioned in the axil of the bract above the foliage leaf in $F$. compressa. In $F$. fugax and $F$. albopurpurea they are subtended by bracts as well as by the foliage leaf. In $F$. albopurpurea the inflorescence bud subtended by the foliage leaf is formed in a cavity in the pseudobulb (Fig. 4A) below the point where the vascular strands to the leaf are recognizable. Above the bud (Fig. 4B), the cavity widens to a slit which further up separates the leaf from the pseudobulb (Fig. 4C). The leaf strands take a peripheral position, filling up the outer wall of the bud cavity. Hence the bud cavity opens to the adaxial side of the leaf. However, the inflorescence does not grow out on this side of the leaf, but eventually penetrates the surface of the pseudobulb to the abaxial side of the leaf (Fig. 5A, the bud ' $\mathrm{O}$ '). In F. fugax (Fig. 4F-J) the leaf-subtended inflorescence bud is formed similarly but situated more peripherally compared to the leaf, so that the leaf strands where they become recognizable are in a position proximal to the bud cavity (Fig. $4 \mathrm{G}-\mathrm{H}$ ). The outer wall of this bud cavity has little vascular supply which may facilitate the penetration of the inflorescence bud. The bract-subtended inflorescences develop in $F$. albopurpurea (Fig. 4D-E) and in F. fugax (Fig. 4J) like those of $F$. parishii and $F$. fimbriata described above (Fig. 3).

F. pardalina (Fig. 1D) has short rhizome segments each 2-5 internodes long and slightly swollen. Branching of the stems is frequently extraordinary, and the extraordinary branches are somewhat rhizome-like at 


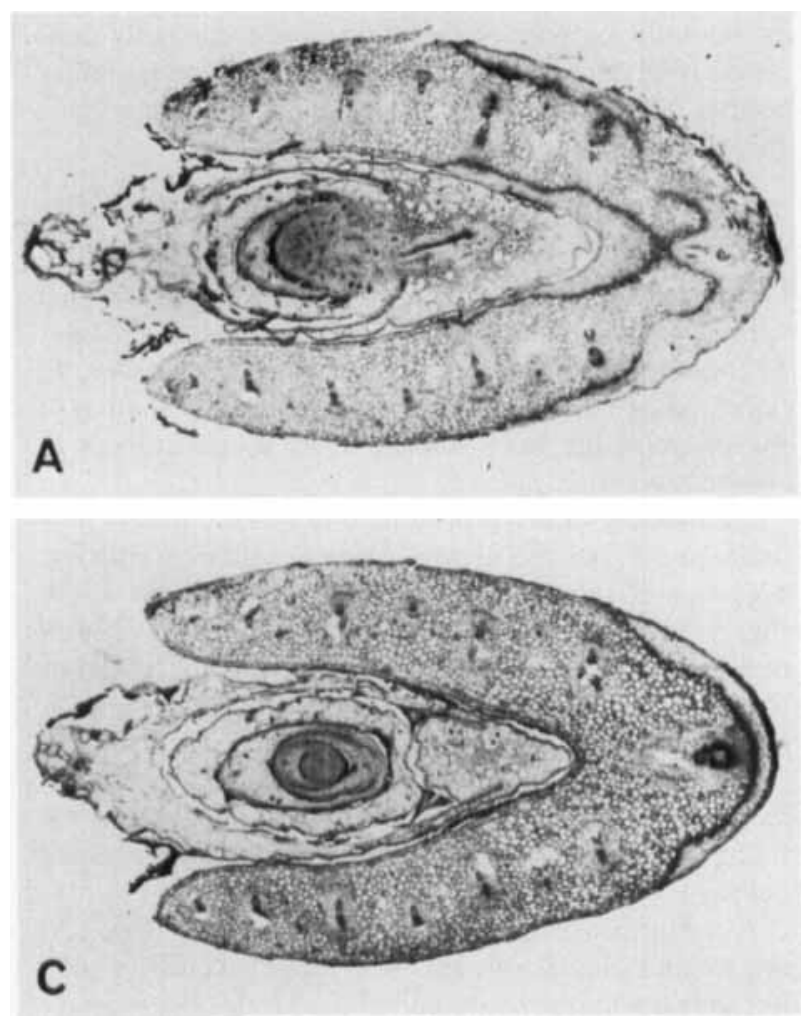

Fig. 3. Ts of top of pseudobulb, sect. Plicatiles. - A-D: Flickingeria parishii. A-B: Foliage leaf (non-sheathing) and a sheathing bract (arrow) surround the top of the stem (s). Bud (b) in the axil of the bract. C-D: Section above A-B. The axillary bud is separated from the apical part of the main stem (s). The bud, a future inflorescence, produces scale leaves, some of which will subtend flowers (not yet developed). -E-F: $F$. fimbriata. Foliage leaf and several bracts have been formed on the stem (s) (the first bracts above the foliage leaf with numbered arrows 1-3). Bract (1) and (2) subtend buds. The bud $\left(b_{1}\right)$ in the axil of $(1)$ has produced three scale leaves, the third of which subtends an axillary bud $\left(b_{1}^{\prime}\right)$. The fourth scale leaf is cut at its base in section $E$, also subtending a bud ( $\left.b_{i}^{\prime \prime}\right)$. Of the bud $\left(b_{2}\right)$ in the axil of (2) two scale leaves are cut in section $E$. Above $E$, in section $F$, seven scale leaves are seen, the sixth one subtending a flower. Note the prophyll (p) and the contour of the ovary (o). Section $F$ is above the apices of the main stem (s) and of $b_{2} .-A-D:$ GT 8387, E-F: Cu 1217. Scales $=3 \mathrm{~mm}, 5 \mathrm{~mm}$.
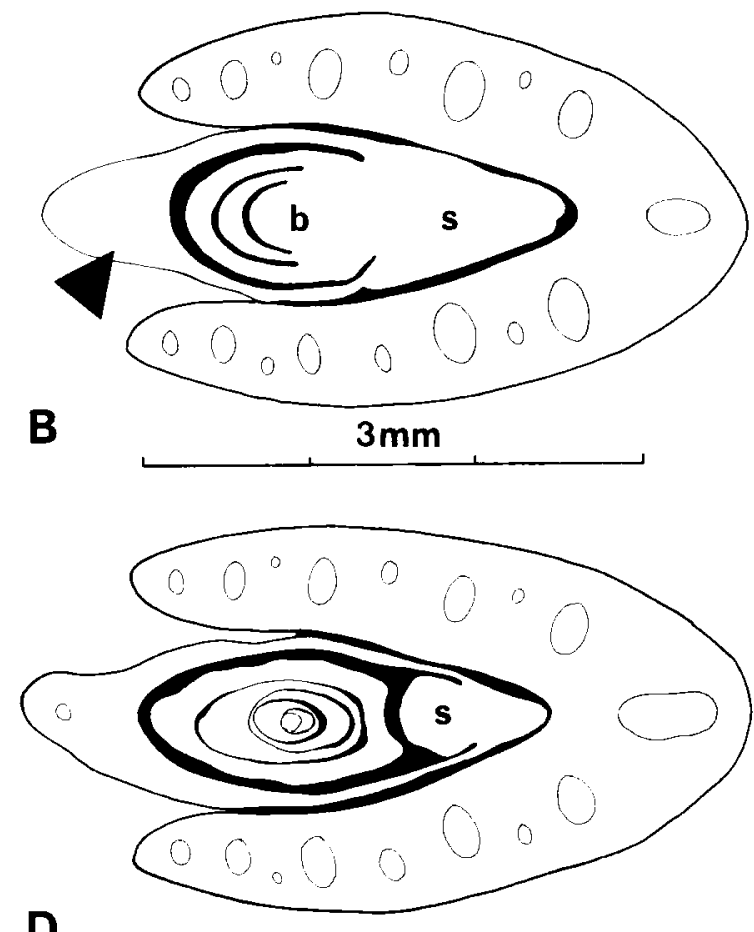

D
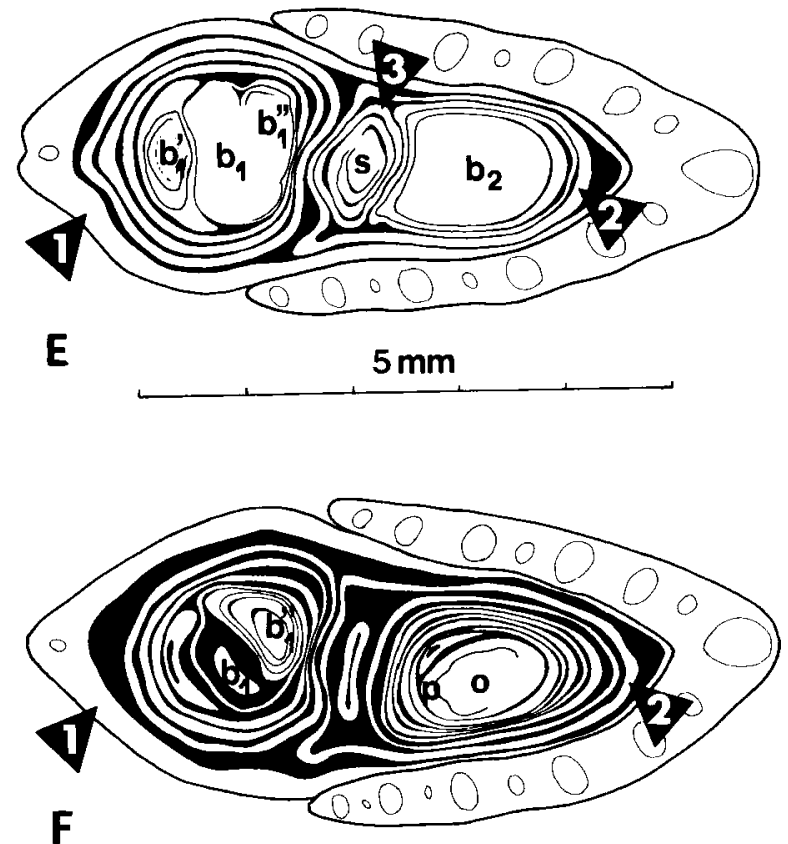

F 

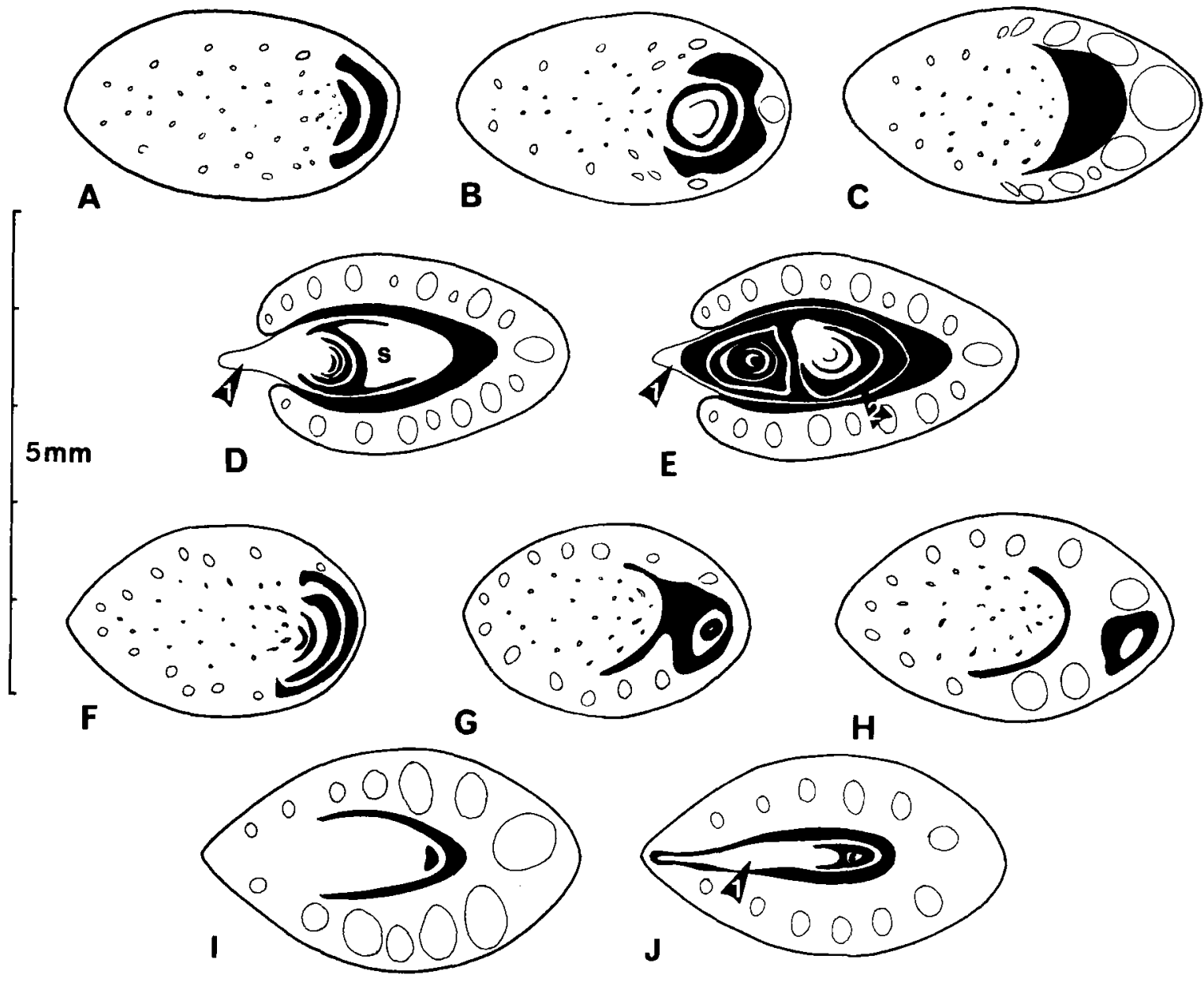

$\mathbf{G}$

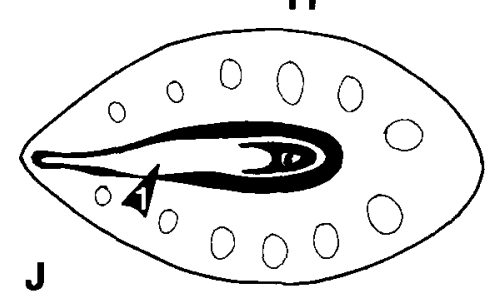

Fig. 4. Ts of top of pseudobulb, at increasing levels, semischematic, sect. Plicatiles. - A-E: F. albopurpurea. A: A bud is formed in a cavity in the stem. B-C: Above this, the strands to the leaf pass out into the peripheral wall of the cavity. D-E: Bracts above the foliage leaf (numbered as in Fig. 3) subtend buds. These have produced some scale leaves, but are resting like the one in the stem at the time of fixation. $-\mathrm{F}-\mathrm{J}: F$. fugax. F: Inflorescence bud formed similarly in a stem cavity. G-H: Strands to the foliage leaf gather from the two sides to meet proximally to the bud. I-J: The bract above the foliage leaf with an axillary bud hardly differentiated at the time of fixation. - A-E: GT 7170, F-J: GT 7818. Scale $=5 \mathrm{~mm}$.

the base and rooting. Inflorescences are bract-subtended, but $F$. pardalina, like $F$. parishii, is peculiar in having also a leaf-subtended bud that does not penetrate to the surface (Fig. 5B). This rudimentary bud was observed in three specimens of this species but inflorescences never occurred in the leaf-subtended position. The main axis normally produces only one bract above the foliage leaf, and ends immediately above this bract.

The two species $F$. pallens and $F$. insularis are very similar in architecture. They are comparatively small species with bushy appearance. The rhizome segments are short, consisting of few, swollen internodes. Branching is frequent, also extraordinary. In $F$. pallens, the branches are not rooting, while in $F$. insularis especially the lower branches are often slightly swollen at the base and rooting. The inflorescence buds are bract- subtended, and more than one may develop on a pseudobulb (Fig. 5C), although one inflorescence is more common.

\section{Section Bilobulatae}

Of this section estimated to include 25 species, material of 6 of the 8 Thai species was available, $F$. angustifolia, $F$. bancana, $F$. convexa, $F$. ritaeana, $F$. unibulbis and $F$. xantholeuca. Serial sections of the top of the pseudobulbs were studied from $F$. bancana, $F$. ritaeana, and $F$. xantholeuca.

One of the species, $F$. convexa (Fig. 1B) differs markedly from the others in this section by having long, slender rhizome segments. This is a very small species, with unbranched erect stems only a few internodes long. 

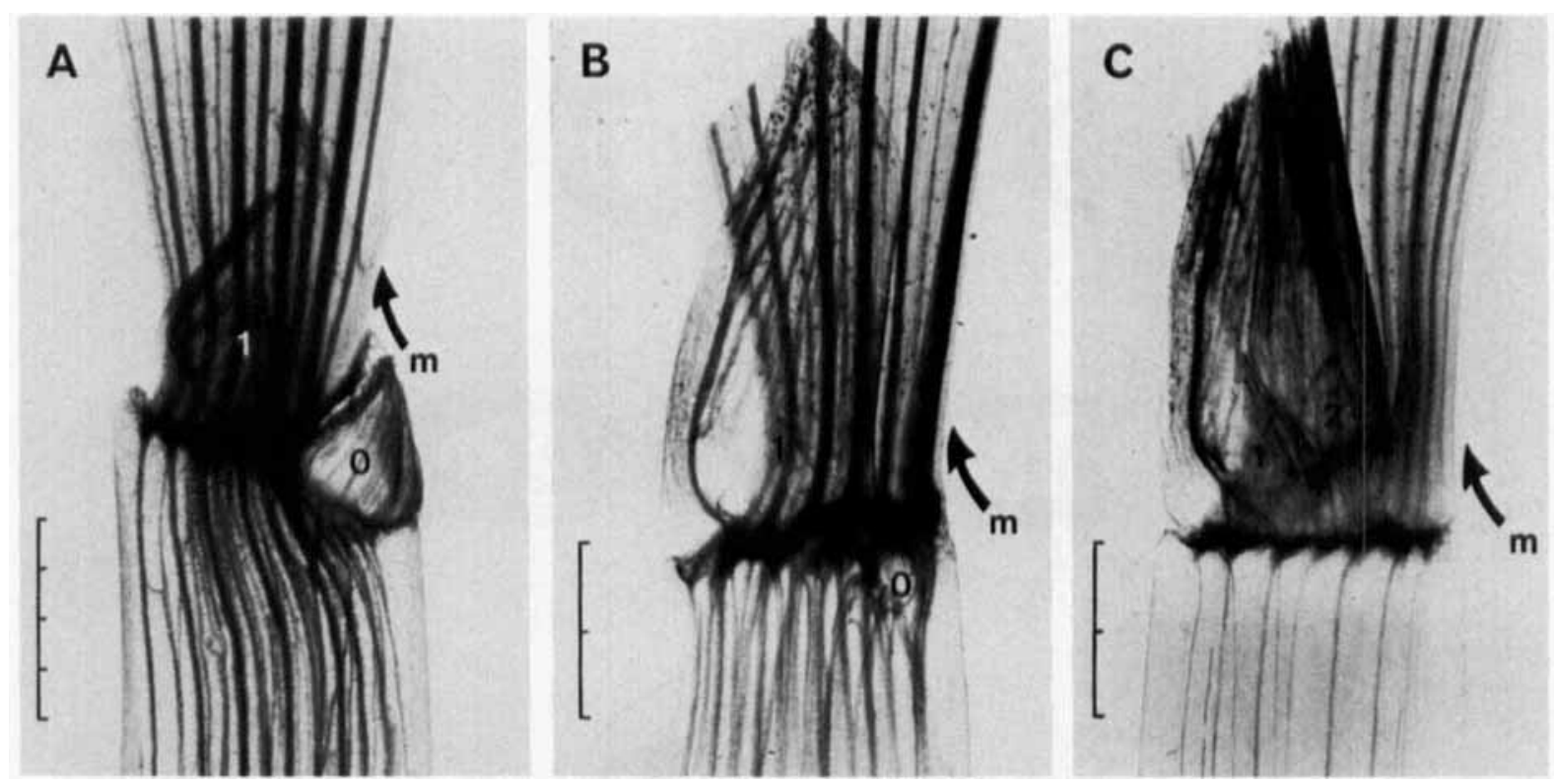

Fig. 5. Top of pseudobulb with basal part of the foliage leaf, sect. Plicatiles. Cleaved along the median line of the leaves, cleared. Foliage leaf showing half of the lamina with median line $(\mathrm{m})$ to the right. - A: Flickingeria albopurpurea, one bud (o) in the axil of (below) the foliage leaf, and one (1) in the axil of a bract above the foliage leaf. - B: $F$. pardalina. The leaf-subtended inflorescence bud $(0)$ rudimentary. Inflorescence from axillary bud $(1)$ of the bract above. - C: $F$. insularis. Leaf-subtended inflorescence bud absent. Flowering from axillary buds of the bracts above (1 and 2). - A: GT 7170, B: GT 5515, C: GT 6481. Scales $=4 \mathrm{~mm}, 2 \mathrm{~mm}$, and $2 \mathrm{~mm}$.

$F$. unibulbis has, like $F$. convexa, unbranched stems, but the rhizome segments are short (Seidenfaden 1980: Fig. 21).

The other species are bushy and richly branched plants. With 4-5 internodes in each, the rhizome segments in $F$. angustifolia are the longest in this group. The rest of the species have shorter rhizome segments, more or less swollen (Fig. 1C, $F$. ritaeana). Extraordinary branching is frequent - an exception is $F$. xantholeuca with only ordinary, often rooting branches (Seidenfaden 1980: Fig. 23).

All species in sect. Bilobulatae have leaf-subtended inflorescences only. This condition is associated with the more or less complete lack of bracts above the foliage leaf and with an extension of the outer layer of the pseudobulb around the bud, reminiscent of a bract. (This extension also occurs in the species of sect. Plicatiles with leaf-subtended inflorescence, only less pronounced). The three species $F$. xantholeuca, $F$. ritaeana, and $F$. bancana represent a progressing series with respect to the degree of inflorescence displacement compared to the subtending leaf, and to the degree to which the apical part of the stem is reduced (Fig. 6). The vascular connection to the bud is placed much below that to the leaf (Figs 6B, D, F; 7A-C). In F. xantholeuca it takes an upward turn before entering the basis of the bud (Fig. 6B). F. xantholeuca has a rudimentary bract above the foliage leaf (Fig. 7F) but the apical dome only just extends above the insertion of this (Fig. 7E). In $F$. ritaeana and $F$. bancana, the apical part of the stem aborts immediately above the foliage leaf.

The strands running in the outer layer of the stem distally to the bud connect with the leaf on the proximal side of the bud (Fig. 7D-G) as they do in F. fugax (sect. Plicatiles, Fig. 4F-J) but the bud cavity does not open out to the adaxial side of the leaf as in that species. This is further discussed below. For some distance the inflorescence bud is placed in a tubular extension of stem origin, adhering to the abaxial side of the leaf (Fig. 7G).

\section{Notes on growth and flowering}

The plants grow intermittently throughout the year, at least under hothouse conditions, but most new shoots appear in spring and in autumn. Any vegetative shoot has a period of maturing and rest before it branches (the branching is proleptic).

The length of new rhizome segments and the number of internodes found in each segment tend to increase, as a plant grows older. Also the number of internodes of the erect stems tends to increase, as does the number of segments in the erect sympodia. The tracing of a sympodium of $F$. pallens and of $F$. fugax backwards into the very centre of the tuft (branching of the rhizome disregarded) will illustrate the case (Fig. 8). This change of habit according to the age of the shoot system occurs within a specific range. In the sympodium of $F$. fugax 


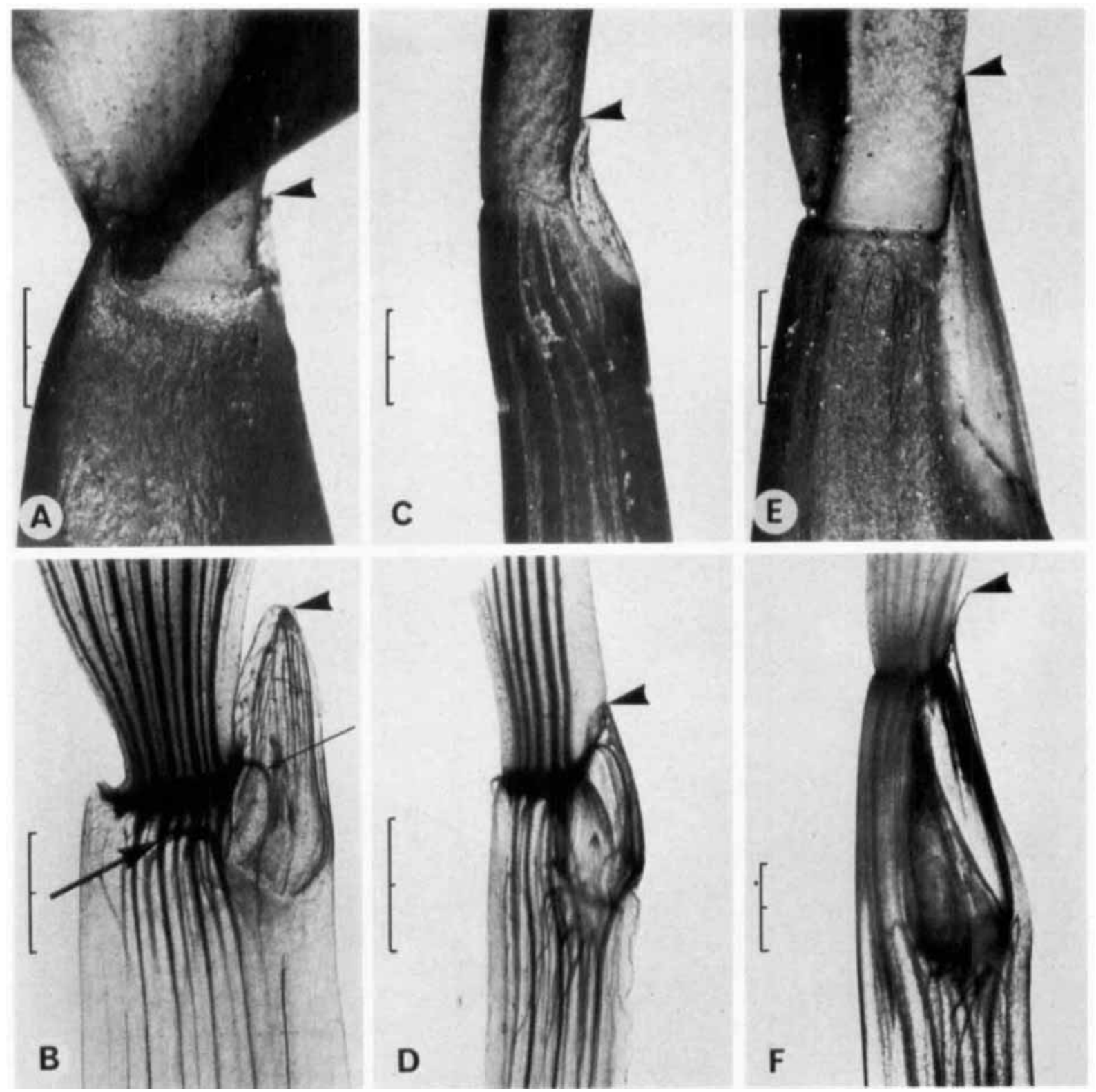

Fig. 6. Top of pseudobulb with basal part of foliage leaf, sect. Bilobulatae. A, C, and E: Exterior view, and B, D, and F: cleaved along the median line of the leaves, cleared and oriented as in Fig. 5. - A-B: Flickingeria xantholeuca. Inflorescence bud subtended by the foliage leaf and situated right behind it. Vascular strands take an upward turn before entering the bud (heavy arrow). The bud is covered by a hood (the top of which is indicated by arrowhead) formed by the outer extended layer of the pseudobulb. Strand passing behind the bud in this layer is seen (small arrow) below its connection with the leaf base (cf. Fig. 7D-F) $-\mathrm{C}-\mathrm{D}: F$. ritaeana and E-F: $F$. bancana. The leaf-subtended inflorescence bud is displaced further down the stem in these species. The hood covering the bud strikingly resembles a bract. - A-B: GT 7586, C-D: GT 3728, E-F: GT 7511. Scales $=2$ $\mathrm{mm}$.

(Fig. 8B) the erect stems have probably reached their optimal height under the actual conditions, while in the sympodium of $F$. pallens (Fig. 8A) each new erect stem seems prepared to overtop the preceding ones both by means of longer segments and by increment of the number of segments.
As mentioned above, inflorescences may function for several growing seasons. It is not unusual to see flowers in old inflorescences $3-4$ axes removed from the top of the erect sympodia. A previous flowering is indicated by the presence of persisting membranous bracts that are left from flowering to flowering. Inflorescences that 

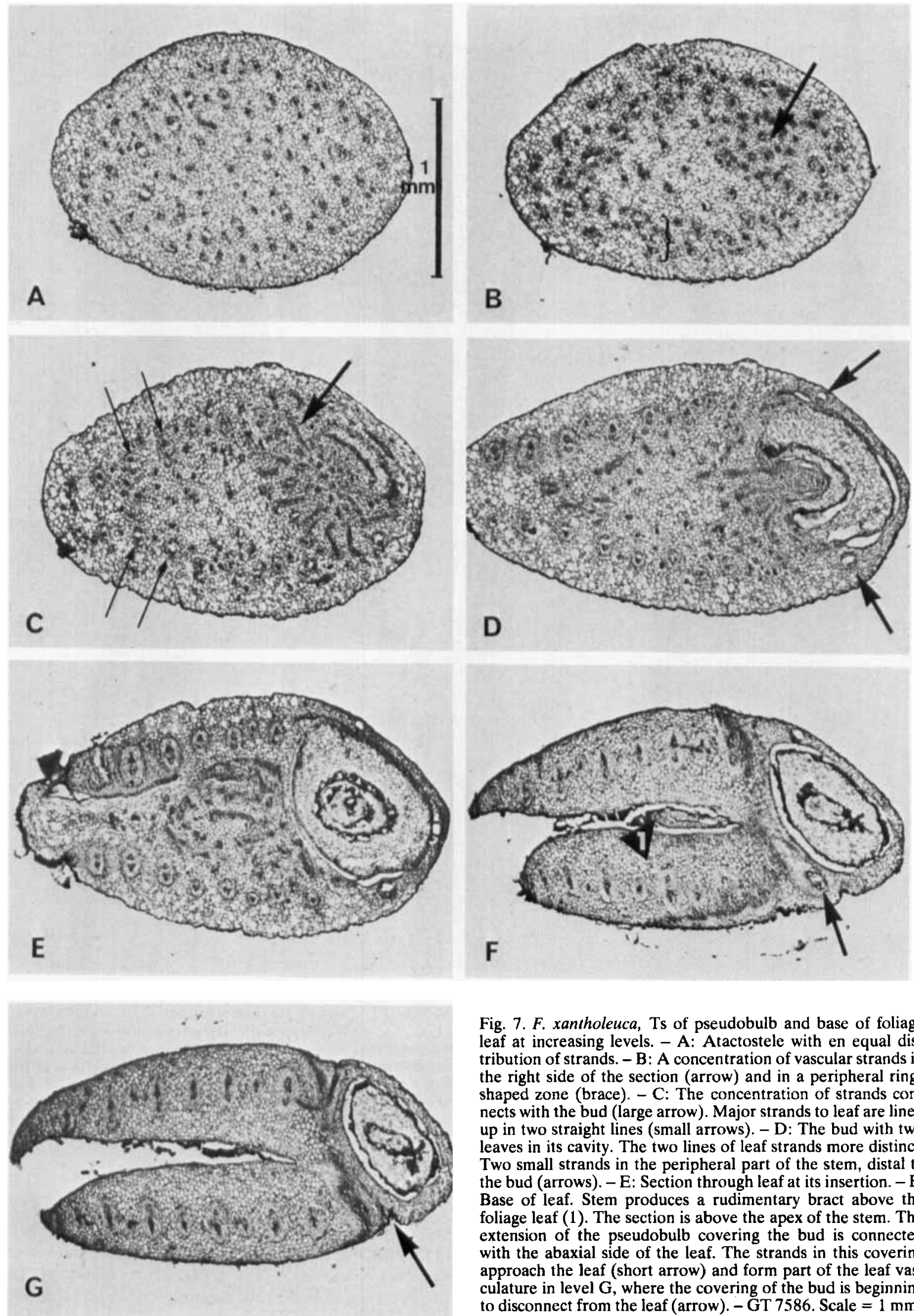

Fig. 7. F, xantholeuca, Ts of pseudobulb and base of foliage leaf at increasing levels. - A: Atactostele with en equal distribution of strands. - B: A concentration of vascular strands in the right side of the section (arrow) and in a peripheral ringshaped zone (brace). - $\mathrm{C}$ : The concentration of strands connects with the bud (large arrow). Major strands to leaf are lined up in two straight lines (small arrows). - D: The bud with two leaves in its cavity. The two lines of leaf strands more distinct. Two small strands in the peripheral part of the stem, distal to the bud (arrows). - E: Section through leaf at its insertion. - F: Base of leaf. Stem produces a rudimentary bract above the foliage leaf (1). The section is above the apex of the stem. The extension of the pseudobulb covering the bud is connected with the abaxial side of the leaf. The strands in this covering approach the leaf (short arrow) and form part of the leaf vasculature in level $\mathrm{G}$, where the covering of the bud is beginning to disconnect from the leaf (arrow). - GT 7586. Scale $=1 \mathrm{~mm}$. 


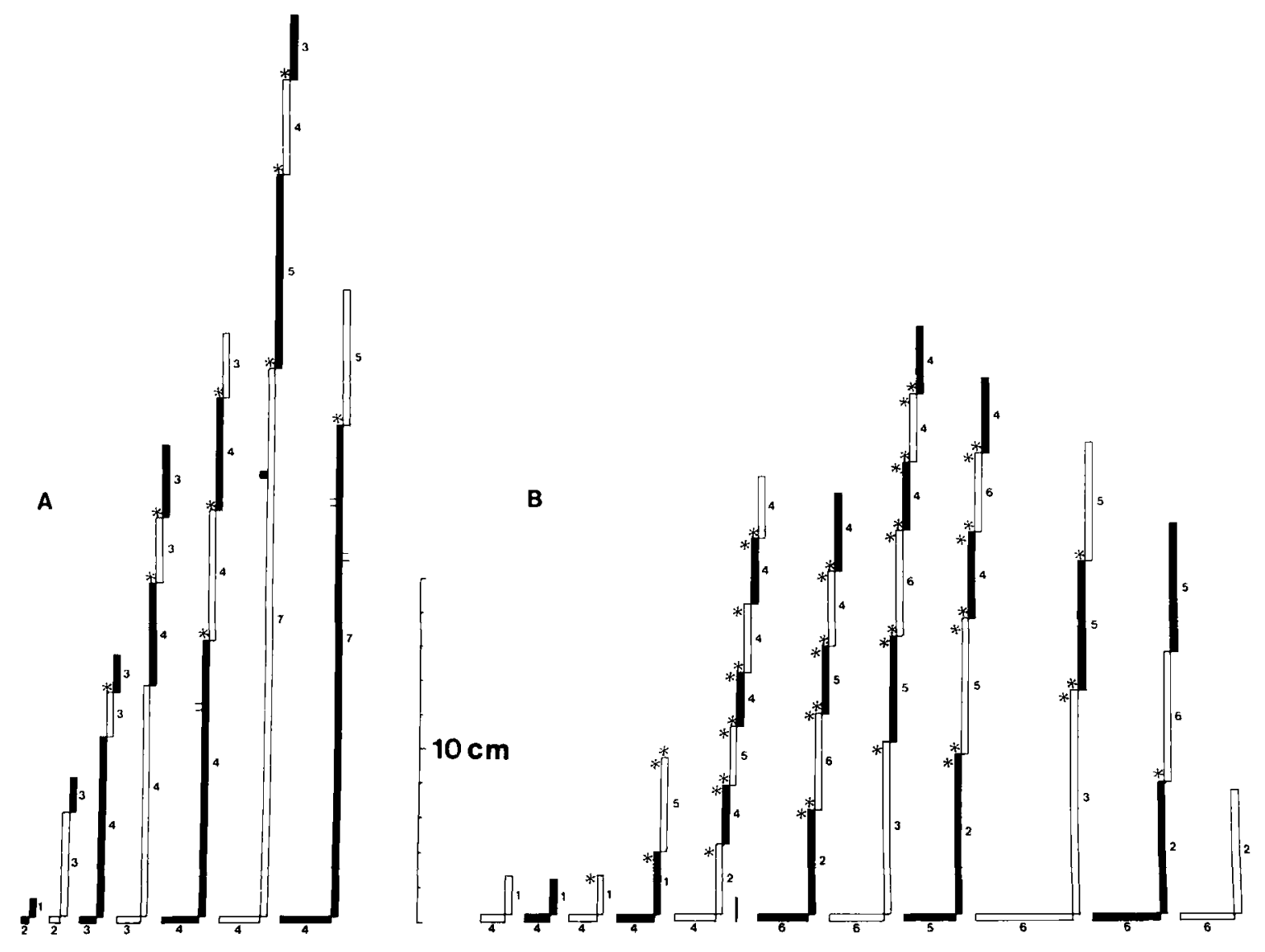

Fig. 8. Schematic representation of shoot systems of $F$. pallens (A) and $F$. fugax (B). Segments all drawn according to their actual length (the pseudobulbous internodes not included); figures indicate number of internodes in each segment. Successive shoot generations alternately black and white. Branching of the rhizome is disregarded, and rhizome segments are spaced to facilitate interpretation. Mark in (B) indicates a damaged rhizome segment, this and the accompanying erect sympodium are left out. The position of extraordinary branches in (A) is indicated by short horizontal lines. Flowering and former flowering on a pseudobulb is indicated by an asterisk, in (B) the one on top of the stem segment refers to the bract-subtended inflorescence, the lower one to the leaf-subtended. - A: GT 6461, B: GT 7818. Scale $=10 \mathrm{~cm}$.

have flowered and may still be functional are indicated by asterisks in Fig. 8 . In the oldest end of the sympodia (Fig. 8) some sterile pseudobulbs in succession are found, hence demonstrating that plants do not flower for quite a number of growing seasons during juvenile stage. In the case of the sympodium of $F$. pallens (Fig. $8 \mathrm{~A}$ ), flowering has not occurred for at least the first 4 growing seasons, and in that of $F$. fugax (Fig. 8B) for at least 3 growing seasons during establishment.

By counting the number of segments distal to a flowering axis an estimate of the age of this segment can be obtained. In some species, a pseudobulb flowers for the first time at the end of its first growing season or at the beginning of its second, i.e. before or while a branching occurs below the pseudobulb in question. This applies to $F$. fimbriata, $F$. pallens (Fig. 8A) and $F$. pardalina that all have bract-subtended inflorescences only (sect. Plicatiles) and to $F$. xantholeuca with leaf-subtended inflorescence (sect. Bilobulatae).
It is, however, far more common that pseudobulbs are at least one shoot generation older before the first flowering takes place. $F$. fugax (Fig. 8B) and $F$. albopurpurea (sect. Plicatiles) with both leaf- and bractsubtended inflorescences flower mainly from pseudobulbs 2-3 growth seasons old. Either of the two inflorescences may be the first to emerge and flower on a particular pseudobulb. $F$. insularis and $F$. parishii in sect. Plicatiles (bract-subtended inflorescence only), and $F$. angustifolia, $F$. bancana, $F$. ritaeana, and $F$. unibulbis in sect. Bilobulatae (leaf-subtended inflorescence only) also represent this condition.

\section{Discussion and conclusions}

The architecture of the species of Flickingeria is modular consisting of three kinds of shoots of limited growth. These modules occur in different proportions 


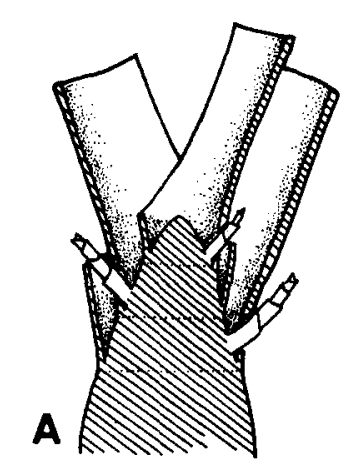

B

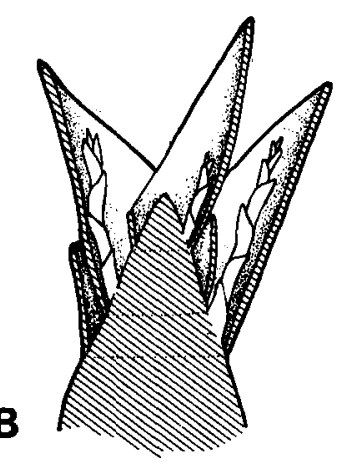

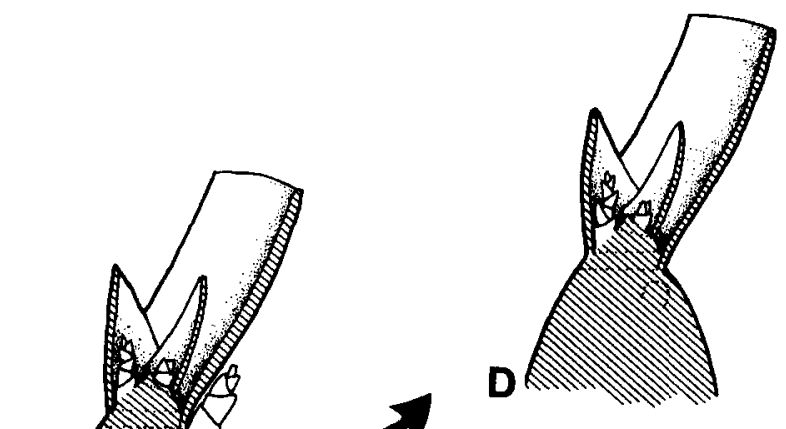
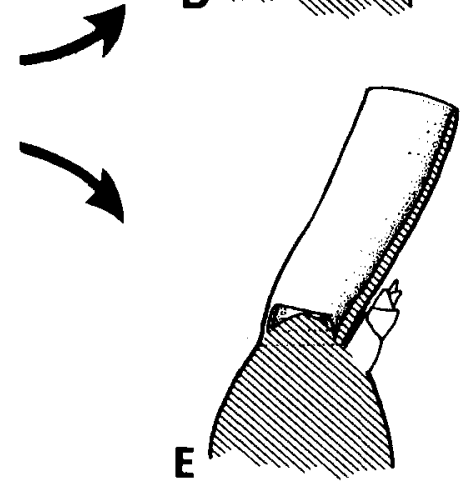

Fig. 9. Schematic representation of inflorescence position in some species of Dendrobium (A-B) and in Flickingeria (C-E). - A: Pseudobulb consists of several internodes, leaves alike, sheathing, subtending inflorescences which break through the sheaths. B: As A, but apical leaves short, inflorescences not breaking through sheaths. - C: Apical internodes of pseudobulb short, pseudobulb consisting mainly of one internode. Foliage leaf without sheath, axillary bud emerging below its basis. Other inflorescences in the axils of bracts above foliage leaf. - D: As C, but inflorescence subtended by foliage leaf reduced. - E: As C, but the apical part of the stem with its appendices much reduced, only one rudimentary bract (as in Fig. 7F) is seen, inflorescence subtended by foliage leaf only.

characteristic of the species. Shoots of type (2), i.e. aerial stems without a rhizomatous basis, may be missing, as in the unbranched species $F$. convexa and $F$. unibulbis. The shoots can be divided into two vegetative parts, the rhizomatous and the erect part, the buds of which have different potential. The fixed branching pattern can be ascribed to the dominance of the most apically placed axillary bud in the two respective parts.

There are specific differences in Flickingeria with respect to the length of the rhizome segments, the length and extent of branching of the erect stems and the position of the inflorescences. In the juvenile stage, the plants have unbranched stems and do not flower. Two of the investigated species, $F$. convexa and $F$. unibulbis, maintain the juvenile growth pattern throughout life.

The number of internodes in each rhizome segment increases up to a certain limit during adolescence. Not even in fully grown plants is the number of internodes exactly determined (Fig. 8). As the scale leaves are distichous, the renewal of the rhizome may occur either to alternating sides, the rhizome growing in a zig-zag pattern, or repeatedly to the same side so that the rhizome follows a curved course (e.g. Fig. 1C). A precise organization of the renewal and branching of the rhizome as described for other monocotyledons (Bell \& Tomlinsom 1980) does not occur in Flickingeria. The advantage of such a regular pattern may be an effective covering of a uniform substrate as stated by these authors. The epiphytic life-form, on the other hand, may favour a more flexible mode of growth.

The pseudobulbous internode defines the border between the vegetative and the floral branching. It is notable, that in $F$. comata (Fig. $1 \mathrm{E}$ ), a more irregular inflorescence position is associated with a pseudobulb not distinctly limited to a single internode.

Abrupt leaf succession from scale leaves below the pseudobulb to foliage leaf and bracts above the pseudobulb is associated with a similarly abrupt transition from stem internode to pseudobulbous internode, and further to rudimentary internodes above the pseudobulb. The pseudobulb confined to one internode, the non-gradual leaf sequence, and the fixed branching pattern all appear to be interrelated character states.

Dressler \& Dodson (1960) considered a pseudobulb consisting of several internodes more primitive than one consisting mainly of a single internode. An overall suc- 


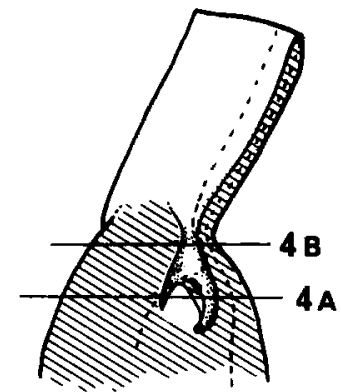

A

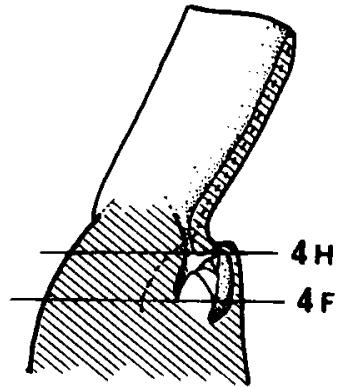

B

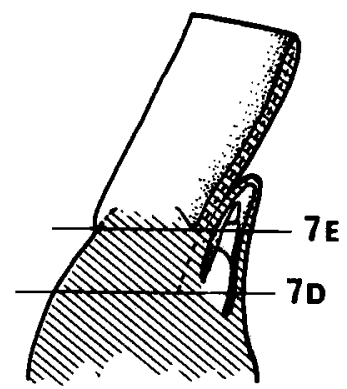

C

Fig. 10. Schematic representation of foliage leaf-subtended inflorescence in three species of Flickingeria. - A: F. albopurpurea. The cavity in which the inflorescence bud is situated is open towards the adaxial side of the leaf base. - B: F. fugax. The bud cavity is closer to the surface of the stem, the outer wall is thin and little vascularized. - C: F. xantholeuca. The bud cavity is closed. The outer wall of the cavity is extended and adnate to the abaxial side of the leaf. In all three species, the bud eventually grows out through the surface of the stem. Horizontal lines refer to transections Figs 4A-B; 4F, H; 7D-E.

culence of the stem would seem easier to establish than a precisely localized swelling of a single internode. Following the considerations above, the pseudobulb consisting of several internodes would be likely to carry uniform leaves and axillary buds with uniform potential In Dendrobium, which for reasons of floral morphology is generally supposed to be closely related to Flickingeria (Seidenfaden 1980), conditions like Fig. 9A and $B$ are found (cf., e.g., the treatment of the New Caledonian species in Hallé 1977). Pseudobulbs, when present, consist of several internodes, and several foliage leaves are found on each pseudobulbous stem. Inflorescences may be subtended by foliage leaves, breaking through the bases of the sheaths (Fig. 9A), or be gathered at the top of the stem subtended by bracts (Fig. 9B). In one species cited by Hallé (1977), $D$. gracilicaule $\mathrm{F}$. Muell., both conditions occur.

An evolution towards the single pseudobulbous internode exhibited in Flickingeria has involved a shortening of the apical internodes and a reduction of the apical leaves into bracts. The loss of the foliage leaf sheath may be a consequence of the close packing of the leaves. This condition (Fig. 9C) is found in Flickingeria (sect. Flickingeria and part of sect. Plicatiles), e.g., in $F$. fugax and $F$. albopurpurea. It is reasonable to assume that this state with all apical appendices present is the ancestral one in Flickingeria. Two evolutionary trends within the genus may be imagined. One leading to a reduction of the leaf-subtended inflorescence (as exhibited in the rest of sect. Plicatiles, Fig. 9D) and one leading to further shortening of the apical part of the stem, so that bracts above the foliage leaf are no longer present (as seen in sect. Bilobulatae, Fig. 9E).

The interpretation of the "abaxial" inflorescence as being foliage leaf-subtended is substantiated by the fact that no bud is ever seen in the regular position in the axil of the foliage leaf. It is further supported by the connection sometimes found between the cavity in which the inflorescence bud is placed and the adaxial side of the leaf. A trend may be seen in the differences between species with "abaxial" inflorescences (Fig. 10). In $F$. albopurpurea (Fig. 10A) the bud is situated in a cavity connected by a slit with the adaxial side of the leaf (cf. also transsections, Fig. 4A-C). The outer wall of the bud cavity is vascularized and some of the vascular strands to the leaf pass through this area. In F. fugax (Fig. 10B) the bud cavity is more peripheral. The outer wall of the bud cavity is thin and little vascularized. Hence no median strand enters the leaf at the base (cf. Fig. 4G-H). F. xantholeuca (Fig. 10C) together with other species of sect. Bilobulatae represent a further elaboration. The bud cavity here is closed, and the extension of its outer wall is pronounced. The inner part of this extension is adnate to the abaxial side of the leaf (cf. Fig. 7C-F).

There is no indication of any torsion of the stem as suggested by Schlechter (1911-14). Because of the long pseudobulbous internode the bud cannot be related to any other foliar organ than the foliage leaf, nor can it be interpreted as a terminal bud in a sympodial shoot system. The position is hence clarified as a downwards displacement of the axillary bud of the foliage leaf. In all species, the base of the foliage leaf lamina is demarcated by an abscission line which is clearly visible at the top of the pseudobulb (e.g. Fig. 6A, C, E). The surface texture and colour change abruptly across this line and the basal leaf meristem is situated in a zone right above (Rasmussen, unpubl. obs.). Hence, it is reasonable to assume the abscission line to represent the true leaf base, so that the foliage leaf is non-sheathing, and interpret the bud cavity as arising within the stem. The position of the bud must be a result of displacement early in the development - the bud is formed within the cavity of the stem below the basis of the leaf before any swelling of the stem has taken place.

The inflorescences, being lateral, would be expected 
to flower for the first time one growth season after development of the carrying stem. However, flowering often lags more than one growth season behind. This is especially pronounced for the leaf-subtended ones that are to break through the outer layers of the stem.

A pseudobulb normally produces only one or two inflorescences and each inflorescence carries only one flower at a time. However, the flowering capacity is very great due to the fact that all pseudobulbs except the very youngest may flower when conditions are optimal. The flowers last only a few hours.

Simultaneous, extensive flowering occurring several times a year is a flowering pattern known from a number of orchid genera (Smith 1926, Coster 1926), and commonly combined with ephemeral flowers. Smith (1926) observed this kind of flowering, designated as a "multiple bang" flowering pattern (Gentry 1974), in several species of Flickingeria growing naturalized under tropical conditions. It was noted that flowering occurred a specified number of days after a certain change of weather. A similar, sudden bloom of F. fimbriata was observed by Seidenfaden (pers. comm.) in Thailand. While this probably is the usual flowering pattern for most species, Smith (1926) characterized one of the species grown by him as flowering without seasonality, "steady state" flowering pattern (Gentry 1974).

The architecture of Flickingeria with numerous stem segments all capable of flowering, and with long-lived and few-flowered inflorescences renders a perfect adaptation to both kinds of flowering pattern. The many few-flowered inflorescences can respond simultaneously to an external stimulus thus creating an effective "bang". In racemes with more flowers developing, the lower ones would necessarily be somewhat more advanced than the upper ones. On the other hand, if the plant for some reason does not receive a stimulus to simultaneous flowering, the numerous inflorescences may flower independently of each other, so that the "steady state" pattern is established. It is notable that the growth pattern hence provides suitable conditions for two different flowering strategies.

Acknowledgements - G. Seidenfaden is thanked for access to his collections and herbarium material, and for discussions during the work. P. Rasmussen attended to the living collec- tion, and L. Larsen and $\mathrm{K}$. Larsen helped with the laboratory work. F. Rasmussen kindly put the Wild M400 Macroscope (granted by the Danish Natural Science Research Council, grant no. 11-1703) at my disposal. The Inst. of Systematic Botany, Univ. of Copenhagen, supplied working facilities during part of the work. The project was partly supported by the Danish Natural Science Research Council, grant no. 11-1857.

\section{References}

Bell, A. D. \& Tomlinson, P. B. 1980. Adaptive architecture in rhizomatous plants. - Bot. J. Linn. Soc. 80: 125-161.

Blume, C. L. 1825. Bijdragen tot de flora van nederlandsch Indie. - Batavia.

Coster, C. 1926. Periodische Blütenerscheinungen in den Tropen. - Ann. Jard. Bot. Buitenzorg 36: 125-162.

Dalzell, N. A. 1852. Contributions to the botany of Western India. - Hookers Bot. J. 4: 292

Dressler, R. L. 1981. The orchids. Natural history and classification. - Harvard Univ. Press, Cambridge, Mass.

- \& Dodson, C. H. 1960. Classification and phylogeny in the Orchidaceae. - Ann. Miss. Bot. Gard. 47: 25-68

Fisher, J. B. 1973. Unusual branch development in the palm Chrysalidocarpus. - Bot. J. Linn. Soc. 66: 83-95.

- 1978. Leaf opposed buds in Musa: their development and a comparison with allied monocotyledons. - Am. J. Bot. 65: 784-791.

- \& Dransfield, J. 1979. Development of axillary and leafopposed buds in Rattan palms. - Ann. Bot. 44: 57-66.

Gentry, A. H. 1974. Flowering phenology and diversity in tropical Bignoniaceae. - Biotropica 6: 64-68.

Hallé, N. 1977. Orchìdacées. - In: Aubreville, A. \& Leroy, J. F. (eds.), Flore de la Nouvelle-Caledonie et dependances. Muséum National d'Histoire naturelle, Paris, Vol. 8: $1-565$.

Holttum, R. E. 1964. Orchids of Malaya. 3. ed. - Government printing office. Singapore.

Rasmussen, F. N. \& Rasmussen, H. 1979. Notes on the morphology and taxonomy of Diceratostele gabonensis (Orchidaceae). - Bull. Jard. Bot. Nat. Belg. 49: 139-148.

Samson, M. A. H. \& Karstens, W. K. H. 1971. Bulbs and bulbils of Ornithogalum caudatum Ait. - Acta Bot. Neerl. 20: $600-610$.

Schlechter, R. 1911-14. Die Orchidaceen von Deutsch Neu-Guinea. - Feddes Repert. Beiheft 1: 1-1079.

Seidenfaden, G. 1980. Orchid genera in Thailand IX. Flickingeria Hawkes and Epigeneium Gagnep. - Dansk Botanisk Arkiv 34, 1: 1-104.

Simpson, J. L. S. 1929. A short method of clearing plant tissues for anatomical studies. - Stain Tech. 4: 131-132.

Smith, J. J. 1905. Die Orchideen von Java. - Flora von Buitenzorg 6: 1-672.

- 1926. Ephemeral orchids. - Ann. Jard. Bot. Buitenzorg 35: $55-70$. 